\title{
Gender and sexual minorities in astronomy and planetary science face increased risks of harassment and assault
}

\author{
Christina R. Richey ${ }^{a}$, Katharine M.N. Lee ${ }^{b}$, Erica Rodgers ${ }^{c}$, and Kathryn B.H. Clancy,d
}

ajet Propulsion Laboratory, California Institute of Technology, Pasadena, CA, USA

bDepartment of Anthropology, University of Illinois at Urbana-Champaign, Urbana, IL, USA

'Space Science Institute, Boulder, CO, USA

dBeckman Institute for Advanced Science and Technology, University of Illinois at Urbana-Champaign, Urbana, IL, USA

\begin{tabular}{l} 
A R T I C L E I N F O \\
\hline Peer Reviewed Article history: \\
Received 1 APR 2019 \\
Revisions Received 22 OCT 2019 \\
Accepted 11 NOV 2019 \\
\hline Keywords: \\
gender minorities \\
sexual minorities \\
harassment \\
assault \\
planetary science \\
astronomy \\
Corresponding Author: \\
C.R. Richey, \\
christina.r.richey@jpl.nasa.gov
\end{tabular}

\begin{abstract}
A B S T R A C T
Lesbian, gay, bisexual, transgender, queer/questioning, pansexual, asexual, and/or nonbinary (LGBTQPAN) people are a vulnerable, yet understudied group in the American STEM workplace. Only recently have efforts been made to assess their workplace experiences and levels of representation in STEM. In this paper, we sought to explore the experiences of LGBTQPAN individuals in the astronomy and planetary science community. We conducted an internet-based survey of the workplace experiences of 474 astronomers and planetary scientists. We hypothesized LGBTQPAN women and gender minority respondents in our sample would observe negative remarks or directly experience verbal or physical harassment in higher proportion compared to cisgender, straight women, a more commonly studied group. We found support for this hypothesis. LGBTQPAN women and gender minorities also observed more homophobic and transphobic remarks from their peers, and were more likely to feel unsafe at work due to their race, sexual orientation, and gender identity, compared to cisgender, straight women. They were more likely to be verbally harassed due to sexual orientation and gender identity, and were fully twice as likely to be physically harassed due to gender or sex. Based on our sample, we suggest that LGBTQPAN women and gender minorities experience a more hostile workplace climate in astronomy and planetary science compared to cisgender, straight women.
\end{abstract}

(c) 2019. All rights reserved.

\section{Introduction}

Consideration of axes of gender and sexual identity representation has been slow in science workplaces, and thus limited data is available on their lived experiences in the sciences. Yet evidence in American workplaces more broadly demonstrates that lesbian, gay, bisexual, transgender, queer/questioning, pansexual, asexual, and/or nonbinary (LGBTQPAN) people are at greater risk for experiencing negative workplace behaviors than many other groups. Members of the LGBTQPAN community (see Table 1 for working definitions of terms) are stigmatized, labeled, verbally and physically harassed, assaulted, and potentially face employment discrimination, workplace discrimination, and termination of employment [Konik \& Cortina, 2008; Rabelo \& Cortina, 2014]. Many members of the LGBT+ community resort to keeping their sexual identity or gender non-conformity private in response to hostile environments or out of fear of discrimination [Eliason et al., 2011]. The trans community faces especially pervasive problems. In a recent survey of trans people, over $50 \%$ of respondents either delayed or hid their gender transitions to avoid discrimination in the workplace, and this discrimination is racialized, with Black, Latinx, and American Indian trans respondents facing significantly more workplace discrimination than white respondents [Grant et al., 2011].

The science workplace experiences of LGBTQPAN populations have been understudied, with the majority of negative workplace behavior studies focusing on cisgender women [NASEM report, 2018], and to a limited extent on racial or ethnic inequalities among cisgender women [Clancy et al., 2017]. The limited research that has been done on sexual harassment and other identity-based harassment on those with minority identities for gender, sexual orientation, or both, suggests that these groups experience even higher frequencies of harassment than the already-vulnerable group of cisgender straight women [Brewster et al. 2012; Brewster 2014; Eliason et al., 2011; Atherton et al., 2016; Yoder and Mattheis, 2016]. For instance, members of the trans community have reported being outed by coworkers [Schilt \& Connell, 2007; Dispenza et al., 2012], being called a former or incorrect pronoun intentionally [Budge et al., 2010; Brewster et al., 2014], being asked inappropriate questions about their surgical status [Grant et al., 2011], and dealing with job discrimination, including termination of employment [Badgett et al., 2007; Brewster et al., 2014]. Atherton et al., 2016 noted that $15 \%$ of LGBT men, $25 \%$ of LGBT women, and $30 \%$ of gender-nonconforming individuals characterized the overall climate of their department or division of their campus and/or workplace as "uncomfortable" or "very uncomfortable". Further, their experience as often isolated, tokenized, or closeted members of their workplace can further limit the abilities of LGBTQPAN people to find allies and resolve conflicts around incivilities, discrimination, or harassment [Ackerman et al., 2018; NASEM report 2018].

It's hard to know whether LGBTQPAN people are especially underrepresented in the sciences, because they are so marginalized as a class that the National Science Foundation has only just started to pilot a program to begin to assess their prevalence in the scientific 
workforce [Langin, 2018]. In a recent survey of physicists, transgender and gender-nonconforming physicists reported the highest levels of exclusionary behavior, adverse climate, and unsupportive policies [Atherton et al., 2016]. Thirty percent of LGBTQPAN respondents reported considering leaving their workplace or school [Atherton et al., 2016]. Those who experienced discrimination or behavior that was exclusionary were also more likely to consider leaving their institutions and/or places of employment [Atherton et al., 2016; Ackerman et al., 2018]. Members of the LGBT+ community in STEM also have lower job satisfaction than both non-LGBT+ STEM professionals, and LGBT+ community members in non-STEM professions [Brewster et al., 2012; Suri, 2015].

\begin{tabular}{|l|l|}
\hline LGBTQPAN & $\begin{array}{l}\text { Lesbian, gay, transgender, queer/questioning, } \\
\text { pansexual, asexual, and/or nonbinary identities. } \\
\text { We use a maximally inclusive term to represent } \\
\text { minority identities in gender identity and/or sexual } \\
\text { orientation. All of these identities were } \\
\text { specifically inquired about in the demographics } \\
\text { portion of our survey. }\end{array}$ \\
\hline LGBT+ & $\begin{array}{l}\text { Lesbian, gay, bisexual, transgender, plus } \\
\text { represents another common shorthand for those } \\
\text { with minority identities of gender identity and/or } \\
\text { sexual orientation. We use this term when } \\
\text { referring to other published research where it is } \\
\text { unclear the inclusivity of the survey items, and/or } \\
\text { when it is the preferred acronym identified by the } \\
\text { study authors. }\end{array}$ \\
\hline Cisgender & $\begin{array}{l}\text { The gender identification of a person when it } \\
\text { matches the gender they were assigned, typically } \\
\text { at or near birth. }\end{array}$ \\
\hline Transgender & $\begin{array}{l}\text { Of, relating to, or being a person whose gender } \\
\text { identity and/or gender expression differs from } \\
\text { what is typically associated with the sex they were } \\
\text { assigned at birth. }\end{array}$ \\
\hline $\begin{array}{l}\text { LGBTQPAN } \\
\text { women and } \\
\text { gender } \\
\text { minorities }\end{array}$ & $\begin{array}{l}\text { This term includes cisgender women who have a } \\
\text { minority sexual orientation identity as well as } \\
\text { transgender and nonbinary people regardless of } \\
\text { their sexual orientation identity. }\end{array}$ \\
\hline
\end{tabular}

Table 1. Glossary of terms. This glossary does not represent absolute definitions of these terms, only our working definitions for the purposes of this paper.

In astronomy and planetary science, regardless of whether the issue is one of LGBTQPAN scientists being underrepresented, underserved, or both, the dominant lived experience and cultural constructions of the field are white, cisgender male, and straight. In our previous paper on this sample, we found not only that women of color reported the highest levels of sexual harassment and assault but that women of color were the most likely to report feeling unsafe at work in the last five years due to their gender $(40 \%$ of women of color in our sample compared to $27 \%$ of white women) [Clancy et al., 2017]. The majority of scientists holding positions of high power, influence, or rank in astronomy and planetary sciences do not hold minority identities. This means that culture, policy, and the perception of climate is dictated largely by white, cisgender, straight men. LGBTQPAN experiences may be less visible to these groups, and so the extent to which holding these identities puts one at additional risk for sexual or other forms of identity-based harassment is likely to be underestimated.

In this paper, we sought to explore the experiences of LGBTQPAN individuals in the astronomy and planetary science community using our previously collected sample [Clancy et al., 2017]. We ask whether LGBTQPAN women and gender minorities experience a more hostile workplace environment than cisgender, straight women. We confine most of our analyses to a comparison between cisgender, straight women and LGBTQPAN women and gender minorities because cisgender men experience such low rates of harassment that their inclusion runs the risk of overstating differences between cisgender straight and LGBTQPAN experiences. We hypothesize that LGBTQPAN women and gender minorities experience a significantly greater hostile workplace environment than cisgender straight women in this sample.

\section{Methods}

This research was conducted under the oversight of the University of Illinois Institutional Review Board (protocol \#15354). The survey was administered electronically on the Survey Monkey website from 5 January to 15 March 2015. To obtain informed consent, the front page of the online survey informed research participants about the study and that continuing past the front page to complete the survey signified consent. We recruited participants through multiple outlets in the planetary science and astronomical sciences community, and additional detail can be found in Clancy et al., 2017. Recruitment intentionally oversampled women due to their small numbers in astronomy and planetary sciences. Participants were not compensated for participation.

As reported in our previous publication [Clancy et al., 2017] the questions were based on a survey on workplace climate in physics conducted by the American Physical Society's Forum of Graduate Student Affairs [Long, 2012] and adapted for the astronomical and planetary scientist community. Participants were asked to respond to questions regarding personal experiences in the workplace in the past 5 years relative to the dates the survey was conducted. If the participant changed positions in the past 5 years, they were asked to answer questions regarding their current workplace and then asked the same set of questions about their previous workplace. In this paper, we only analyze answers regarding experiences in the current workplace. Participants were asked to provide demographic information about their gender, gender identity, race and ethnicity, and ability status at the end of the survey. The supporting information provides a complete list of survey questions.

The personal experience questions were categorized into three sections: (1) negative language, (2) safety, and (3) responses to harassment. Participants were asked how often they hear negative language from their peers, supervisors, or others (regarding language either directed at themselves or others), regarding sexual orientation, race, sex, gender, femininity/masculinity, physical or mental ability, or religion. Participants were then asked to identify if they feel unsafe due to personal characteristics related to these same factors, and subsequently if they skipped any type of activity (school or work related) because they felt unsafe. The safety section ends by asking respondents if they encountered verbal or physical harassment because of their personal characteristics, and if so, they 
were asked to identify if the harasser(s) was a peer, supervisor, or another member of their school or work community.

We grouped together all individuals who self-identified in one of the following ways: sexuality as lesbian, gay, bisexual, questioning, queer, pansexual, asexual; gender as transgender; or gender as nonbinary, and are labelling this broad category "LGBTQPAN." We regret the error of not providing an option for intersex individuals. We understand that lived experiences are qualitatively different for people across and between these categories, however we also take seriously the privacy of participants holding these identities given the low numbers of most of these categories among astronomers and planetary scientists. While the barriers to acceptance are different among these identities, the effects of sexist, heteronormative, and/or transphobic work climates, should they exist in this sample, are likely to be experienced by most people in this grouping.

If someone identified strictly as cisgender and straight, they are categorized as "Cis, straight." Fifty-seven participants did not report any identities in these categories, thus they are not included in these analyses.

In these analyses, we mostly compare the experiences of cisgender straight women $(n=222)$ with LGBTQPAN women and gender minorities $(n=52)$. Because this data was originally collected to examine the experiences of women in astronomy and planetary science and is a common reference group in studies of sexual harassment, this dataset intentionally oversampled women. Some descriptive statistics involved all respondents who reported gender and gender identity; these are clearly noted. Otherwise for this follow-up analysis, we excluded cis men ( $n=120$ cis straight men, $n$ $=12$ LGBQPAN men) in order to more directly compare the experiences of cis straight women with women and gender minorities across the LGBTQPAN spectrum. Therefore, we did not remove trans men from our analyses.

We used Fisher's Exact test to test if the frequency of hearing negative comments in the workplace, experiences feeling unsafe in the workplace, or number of events skipped due to feeling unsafe differed between LGBTQPAN respondents and cis, straight respondents. Significance was set at alpha $=0.05$, however this means that for two-tailed tests, significance will be at alpha $=0.025$. We report effect size along with $\mathrm{p}$ values rather than performing Bonferroni corrections because Bonferonni corrections decrease statistical power and increase the risk of Type II error [Nakagawa 2004]. Cramér's $V$ was calculated to measure effect size using the LSR package [Navarro 2015] for those analyses where performing a Fisher's Exact test on the continency tables indicated significant results. We follow convention to categorize effects as small ( $V=0.10$ to 0.30$)$, medium ( $V=0.30$ to 0.50$)$, and large $(V>=0.50)$ [Mangiafico 2016]. All analyses were performed in $R$ version 3.5.1 [R core team, 2018] using ggplot2 and dplyr packages [Wickham, 2016; Wickham et al., 2018].

\begin{tabular}{|c|c|c|}
\hline $\begin{array}{l}\text { National Surveys and Activities in } \\
\text { Planetary \& Astronomy }\end{array}$ & & Greater US Laws, Policies, and Rulings \\
\hline \multirow[t]{2}{*}{$\begin{array}{l}\text { 1992: The GLB Astronomy (Now the GLBTQastro List) } \\
\text { email distribution list is formed. The group begins } \\
\text { organizing networking events for members of the } \\
\text { LGBT+ community at American Astronomical Society } \\
\text { (AAS) Meetings. }\end{array}$} & $\begin{array}{c}1990 \\
- \\
1996\end{array}$ & $\begin{array}{l}\text { 1990: The Hate Crimes Statistics Act become the first federal statute to recognize gay, lesbian, and bisexual } \\
\text { people. } \\
\text { 1990: George HW Bush signed the Immigration Act of 1990, which no longer allowed for homosexuality to be } \\
\text { used as a basis for barring entry to the United States. } \\
\text { 1993: "Don't Ask, Don't Tell" is signed into law by President Clinton, prohibiting openly gay and lesbian } \\
\text { Americans from serving in the military. } \\
\text { 1995: The Hate Crimes Sentencing Enhancement Act goes into effect. }\end{array}$ \\
\hline & $\begin{array}{l}1996 \\
-2008\end{array}$ & $\begin{array}{l}\text { 1996: President Clinton signs into law the Defense of Marriage Act. } \\
\text { 2003: The US Supreme Court strikes down the "homosexual conduct" law. } \\
\text { 2008: Proposition } 8 \text { is approved by voters in California, making same-sex marriage illegal. }\end{array}$ \\
\hline $\begin{array}{l}\text { 2011: The National Transgender Discrimination Survey } \\
\text { (NTDS) is released. } \\
\text { 2012: The AAS establishes the Working Group on } \\
\text { LGBTIQ Equality (WGLE). } \\
\text { 2015: The CSWA Survey on Workplace Climate results } \\
\text { (which this paper analyzes) are gathered from the } \\
\text { community. } \\
\text { 2015: WGLE officially become the AAS Committee for } \\
\text { Sexual-Orientation and Gender Minorities in } \\
\text { Astronomy (SGMA). } \\
\text { 2016: The US Transgender Survey, the } 2^{\text {nd }} \text { report from } \\
\text { the NTDS, is released. } \\
\text { 2016: The American Physical Society released it's LGBT } \\
\text { Climate in Physics Report. } \\
\text { 2016: The Division for Planetary Sciences creates the } \\
\text { Professional Culture and Climate Subcommittee. }\end{array}$ & 2016 & $\begin{array}{l}\text { 2016: The US Depts of Education (ED) and Justices (DOJ) issue guidance that schools provide transgender } \\
\text { students access to sex-segregated activities and facilities consistent with their gender identity. } \\
\text { 2016: The Public Facilities Privacy and Security Act in North Carolina, which limited the use of bathrooms to } \\
\text { the sex identified in an individual's birth certificate, was approved. Portions of the measure were repealed in } \\
\text { 2017. } \\
\text { 2016: California becomes the first state (after several local and city ordinances) to require all single-toilet } \\
\text { bathrooms be designated gender neutral. }\end{array}$ \\
\hline $\begin{array}{l}\text { 2018: The LGBT+ Inclusivity in Physics and Astronomy: } \\
\text { A Best Practices Guide ( } 2^{\text {nd }} \text { Edition) is released jointly } \\
\text { by the AAS SGMA and the LGBT+Physicists Group. }\end{array}$ & & $\begin{array}{l}\text { 2017: The } 7^{\text {th }} \text { Circuit of Appeals rules that the Civil Rights Act prohibits workplace discrimination against LGBT } \\
\text { employees. } \\
\text { 2017: The US Depts of Education (ED) and Justice (DOJ) rescinds guidance extending sexual discrimination } \\
\text { protections under Title IX to trans students, including for the } 2016 \text { facilities based on gender identity. The } \\
\text { Office for Civil Rights (OCR) halted several Title IX investigations involving trans students. }\end{array}$ \\
\hline
\end{tabular}

Figure 1. Timeline of policies and protections for LGBT+ community members (primarily at the federal level) within the United States, as well as efforts within the astronomical and planetary science communities to build community groups, committees, and survey efforts that are referred to within this paper. The goal of this paper is to understand workplace climate issues as they relate to the LGBTQPAN community within our respondents. The survey results for our study were acquired from 5 January to 15 March 2015, during one of the highest points of protections within the United States for LGBT+ community members. 


\section{Results}

Participants across all identity groups reported high rates of both observing and directly experiencing verbal and physical harassment. For example, $62 \%$ of all cisgender male respondents (118 cis, straight men and 12 cis men who reported a sexual orientation other than straight) in this sample indicated that they had heard sexist comments from their peers in their work environment in the last five years; for cisgender straight women that number climbed to $78 \%$ and for LGBTQPAN women and gender minorities that number was $81 \%$ (see Figure 2). $3 \%$ percent of cisgender male respondents experienced verbal harassment of a sexist nature; for cisgender straight women that number was $40 \%$ and for LGBTQPAN women and gender minorities that number was $47 \%$. Physical harassment due to sex was reported by $0 \%$ of cisgender male respondents, $9 \%$ of cisgender straight women, and $21 \%$ of LGBTQPAN women and gender minority respondents.

We next compared the observations and direct experiences of cisgender, straight women ( $\mathrm{n}=222$ ) with LGBTQPAN women and gender minorities $(n=59)$ in our sample. We found a significant difference between the frequency of hearing negative remarks from peers when we compare the experiences of women and gender minorities who identify as LGBTQPAN versus cis, straight women. LGBTQPAN women and gender minorities were more likely to observe negative remarks that were homophobic $(p=0.002, V=0.22)$, were transphobic $(p<0.001, V=0.34)$, and were about religion or a lack thereof $(p=0.001, V=0.23)$ from their peers. The frequency of hearing negative remarks from supervisors was also greater for LGBTQPAN women and gender minorities for racist remarks $(p=0.01, V=0.21)$ and religion or lack thereof $(p=0.014$, $V=0.20$ ); for negative remarks from others, more LGBTQPAN women and gender minorities observed transphobic remarks $(p=0.02, V=0.20)$. Additional detail is available in Supplemental Table A.

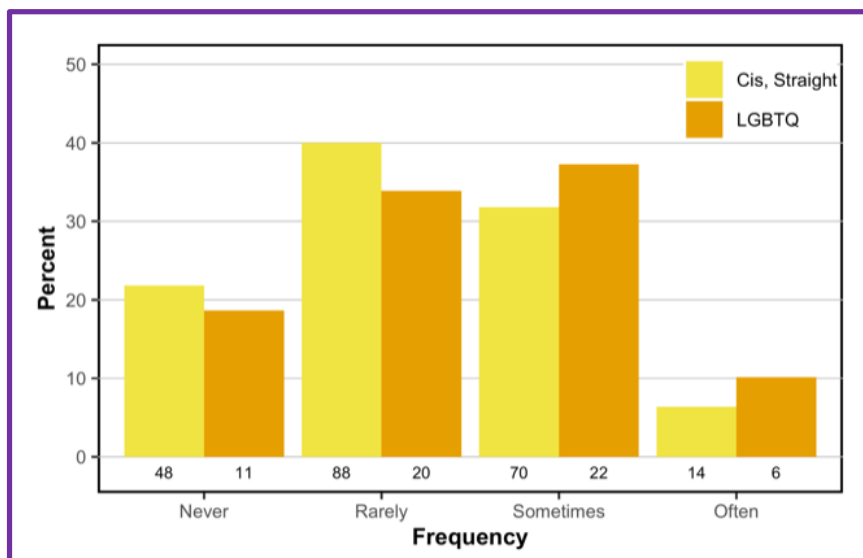

Figure 2. Frequency of hearing sexist remarks from peers in the workplace. Only cis, straight women and LGBTQPAN women and gender minorities are included in this graph.

When we asked if people have felt unsafe at their current position due to any of the listed personal characteristics, LGBTQPAN women and gender minorities were more likely to feel unsafe due to their race $(12 \%$ for LGBTQPAN women and gender minorities vs $4 \%$ for cis, straight women; $p=0.02, V=0.15$ ), sexual orientation ( $10 \%$ for LGBTQPAN women and gender minorities vs $0 \%$ for cis, straight women; $p<0.001, V=0.24$ ), and gender identity ( $14 \%$ for LGBTQPAN women and gender minorities vs $0 \%$ for cis, straight women; $p<0.001, V=0.31$ ). There was no significant difference in feeling unsafe due to gender, likely because it was common for both groups ( $28 \%$ for cis, straight women vs. $34 \%$ for LGBTQPAN women and gender minorities). For additional details, see Supplemental Table B. There were no significant differences between groups for the number of events skipped due to feeling unsafe ( $13 \%$ cisgender vs $16 \%$ LGBTQPAN, $p=0.18, v=0.15$ ).

Finally, verbal harassment due to sexual orientation was higher ( $p=0.005, V$ could not be calculated due to zeros in table), and physical harassment due to gender or sex was higher $(p=0.006$, $V=0.21$ ), for LGBTQPAN women and gender minorities. Table 2 shows that $21 \%$ of LGBTQPAN women and gender minorities report experiencing physical harassment in the workplace within the 5 years prior to the survey administration dates, more than twice the incidence reported in our sample of cisgender, straight women (9\%). Supplemental Tables $C$ and D show responses to all questions about verbal and physical harassment.

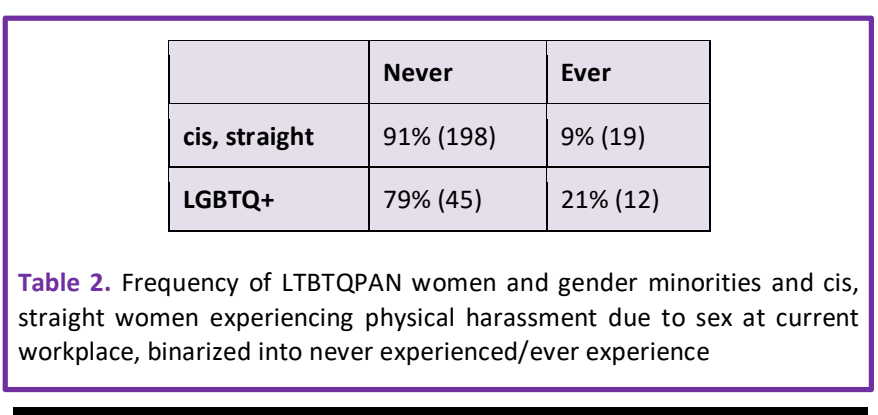

4. Discussion

LGBTQPAN women and gender minorities in this sample reported a high rate of observing negative remarks, as well as directly experiencing verbal harassment and physical harassment in their astronomy and planetary science workplaces. We remind the reader that the survey responses for this study were acquired during one of the highest points of protection within the United States for the LGBTQPAN community (see Figure 1). Our survey methodology also tightly defined the context of the study as being in respondents' current position, over just the last five years (20112015) to limit recall bias or inclusion of long past events that may have occurred in a differently inclusive work environment.

Not only did LGBTQPAN women and gender minorities observe more homophobic and transphobic remarks than their cisgender, straight female peers, they were more likely to feel unsafe at work due to their race, sexual orientation, and gender identity. They were more likely to be verbally harassed due to sexual orientation and gender identity. Finally, they were more than twice as likely to be physically harassed due to gender or sex. As has been shown previously with this sample, women generally have already been shown to experience a more hostile environment than men [Clancy 
et al 2017]. We again assert that the negative experiences reported in this sample constitute a hostile workplace environment.

The hostile workplace environment experienced by LGBTQPAN women and gender minorities may add to the burden of considering personal well-being and safety when travelling for work (i.e. for conferences, observing runs, geology field trips). Whether employed in higher education, government, or industry, LGBT+ members of academic and professional communities need to consider their travel location's discriminatory practices and laws, access to bathrooms, as well as the increased likelihood for violence, in ways that cisgender straight folks often do not [Ackerman et al., 2018].

Members of the LGBTQ+ community have heightened levels of stress, anxiety, depression, substance abuse, and suicide attempts, in large part due to the overall negative cultural climate and discriminatory practices they face throughout their lives [Brewster et al., 2012]. Members of the trans community show higher rates of feeling excluded, dealing with intersectional verbal and physical harassment and assault, and dealing with higher rates of prejudice [Lombardi et al., 2002; Grant et al., 2011; Brewster et al., 2014; Atherton et al., 2016]. Our work firmly establishes that LGBTQPAN folk within the astronomy and planetary science community also experience this hostile environment at work. Diversity of thought is paramount to identifying robust STEM research questions, problem identification, and data interpretation [Watson et al., 1993; Wright et al., 1995; McLeod et al., 1996; Burt, 2004; Vedres \& Stark, 2010; Neff, 2012]. We must be inclusive and constantly practice being allies, advocates, and accomplices with our colleagues in the LGBTQ+ community to achieve advances in astronomy and planetary science.

\section{Recommendations}

As with our previous paper on this data set [Clancy et al., 2017], the recent APS LGBT+ best practices report [Ackerman et al., 2018], and the National Academies of Science, Engineering, and Medicine (2018) report on sexual harassment, we seek not only to highlight a problem but also to provide a path toward a more inclusive and equitable scientific community. The research strongly indicates that:

- Institutional leadership should prioritize the physical, sexual, and psychological safety of all their workers. They need to clearly communicate and provide incentives and rewards to motivate culture change.

- Institutions should conduct climate surveys that employ subject matter experts, not just survey method experts. They should swiftly address issues revealed by these assessments but also recognize that there are actions they can take, today, to lessen the impact of a hostile work environment on their LGBTQPAN colleagues and their allies.

- Institutions should develop codes of conduct with clear language about what constitutes appropriate professional behavior. There should be swift sanctions for transgressions of behavior graded to the severity of the issue (e.g., a conversation with one's boss, additional training, probation, demotion, or termination).

- Institutions should consider restorative capacity building practices to develop bystander intervention skills in all workers, a sense of responsibility for the culture and climate of the institution at all levels, including at the top, and informal practices to encourage conversation and "calling in" where relevant. Institutions can also educate the astronomy and planetary science workforce through perspective-taking trainings to inform the broader community on the lived experience of being LGBTQPAN.

- Institutions should work to identify and support LGBTQPAN networking opportunities, allies, and initiate a discussion of LGBTQPAN workplace concerns.

- Institutions should ensure equal access to bathroom facilities for all genders.

- Institutions should encourage safe/inclusive practices of sharing gender pronouns and using preferred gender pronouns.

- Institutions should require all research partners to have inclusive LGBTQPAN policies. Travel considerations for LGBTQPAN individuals should be explicitly considered by conference organizers, field school program directors, and observatory directors, rather than existing as an extra burden or barrier for LGBTQPAN members of the community.

Supportive workplace climates that include non-discrimination policies or other protective practices are related to job satisfaction and affective commitment to the workplace [Bouzianis at al., 2008; Brewster et al., 2012]. LGBT+ people who work in these supportive workplace climates are more likely to be out at work or more likely to disclose transgender identity at work [Brewster, 2014 and references within; Gates \& Viggiani, 2014 and references within]. Environments where disclosure worsens the workplace experience, or where the workplace is not deemed safe enough to disclose, carries the consequence of increasing cognitive burden and worsening the home environment for those LGBTQPAN folks who cannot be "out" [Madera, 2010; Ozeren 2014; Botti et al., 2015; Williamson et al., 2017].

In addition to encouraging institutions to take the above actions, individuals in the astronomy and planetary science can all work to set better examples and expectations for professional behavior. Allies and advocates need to practice inclusive workplace behavior, and be willing to hear criticism and improve. Leaders in the field need to model appropriate behavior and define an inclusive and equitable culture in their workplaces, disciplines, and professional societies [Settles et al., 2006; Cortina et al. 2013; Clancy et al., 2014]. Allies should engage in dialog regarding preferred pronouns through respectful discourse and email signature annunciation [Ackerman et al., 2018; Grant et al., 2011].

Many of the above recommendations reflect the kinds of inclusive workplaces that reduce rude and contemptuous behaviors and many types of identity-based harassment broadly, and frankly create a more enjoyable workplace for people of all identities. Inclusive workplaces are ones that are more equitable, friendly, 
and in the end, more productive and innovative. Astronomy and planetary science are disciplines already starting to be attuned to these issues, with grassroots efforts like the Inclusive Astronomy Conference and the Astronomy Allies. These efforts and their leaders deserve more structural support from their departments and professional societies to see positive change.

\section{Acknowledgements}

Aggregated, de-identified data are provided in the tables and supplemental information. We thank the American Astronomical Society (AAS) and the AAS's Committee for the Status of Women in Astronomy for funding to support this research, and the anonymous reviewers who strengthened this manuscript considerably. C.R. Richey would like to thank Jet Propulsion Laboratory's Raise the Bar, under a contract with National Aeronautics and Space Administration, for partial funding for their time and efforts. K.B.H. Clancy would like to thank the Illinois Leadership Center Faculty Fellow Program for funding her time and efforts. But most of all, we thank the astronomers and planetary scientists who participated in this research.

\section{REFERENCES}

Ackerman, N., Atherton,T. J., Avalani, A. R., Berven, C. A., Laskar, T., Neunzert, A., Parno, D. S., \& Ramsey-Musolf, M. (2018). LGBT+ Inclusivity in Physics and Astronomy: A Best Practices Guide, https://arxiv.org/abs/1804.08406.

Atherton, T. J., Barthelemy, R. S., Deconinck, W., Falk, M. L., Garmon, S., Long, E., Plisch, M., Simmons, E. H., \& Reeves, K. (2016). LGBT Climate in Physics: Building an Inclusive Community (American Physical Society, College Park, MD). URL: https://www.aps.org/programs/lgbt/upload/LGBTClimateinPhysicsReport. pdf

Badgett, M. V. L., Lau, H., Sears, B., \& Ho, D. (2007). Bias in the workplace: Consistent evidence of sexual orientation and gender identity discrimination. URL: https://williamsinstitute.law.ucla.edu/wpcontent/uploads/Badgett-Sears-Lau-Ho-Bias-in-the-Workplace-Jun2007.pdf.

Botti, F., A. Conte, and C. D'Ippoliti, (2015). Not so classy after all: Identity utility and the risk of discrimination of LGB people. MPRA Paper No, 65125. http://mpra.ub.uni-muenchen.de/65125/.

Bouzianis, B., Malcolm, J., \& Hallab, L. (2008). Factors Associated with Sexual Identity Disclosure in the Workplace by Gay Men and Lesbians: A Couples Study. 4 (3), 166-175. URL: http://handle.uws.edu.au:8081/1959.7/559252.

Brewster M. E., Velez B., DeBlaere C., \& Moradi B. (2012). Transgender individuals' workplace experiences: the applicability of sexual minority measures and models., J Couns Psychol. 59(1), 60-70. http://dx.doi.org/10.1037/a0025206.

Brewster, M. E., Velez, B. L., Mennicke, A., \& Tebbe, E. (2014). Voices from beyond: A thematic content analysis of transgender employees' workplace experiences. Psychology of Sexual Orientation and Gender Diversity, 1(2), 159-169. http://dx.doi.org/10.1037/sgd0000030.

Budge, S. L., Tebbe, E. N., \& Howard, K. A. S. (2010). The work experiences of transgender individuals: Negotiating the transition and career decisionmaking processes. Journal of Counseling Psychology, 57, 377-393. http://dx.doi.org/10.1037/a0020472.

Burt, R. (2004). Structural Holes and good Ideas. American Journal of Sociology, 110(2), 349-399. https://www.jstor.org/stable/10.1086/421787.

Clancy, K., Nelson, R., Rutherford, J., \& Hinde, K. (2014). Survey of Academic Field Experiences (SAFE): Trainees report harassment and assault, PLoS One, 9(7), e102172. https://doi.org/10.1371/journal.pone.0102172.
Clancy, K. B. H., Lee, K. M. N., Rodgers, E. M., \& Richey, C. (2017). Double jeopardy in astronomy and planetary science: Women of color face greater risks of gendered and racial harassment. Journal of Geophysical Research Planets, 122, 7, 1610-1623. https://doi.org/10.1002/2017JE005256.

Cortina, L. M., Kabat-Farr, D., Leskinen, E. A., Huerta, M., \& Magley, V. J. (2013). Selective incivility as modern discrimination in organizations evidence and impact, J. Manag., 39(6), 1579-1605. https://doi.org/10.1177/0149206311418835.

Dispenza, F., Watson, L. B., Chung, Y. B., \& Brack, G. (2012). Experience of career-related discrimination for female-to-male transgender persons: A qualitative study. The Career Development Quarterly, 60, 65-81. http://dx.doi.org/10.1002/j.2161-0045.2012.00006.x.

Eliason, M. J., Dibble, S. L., \& Robertson, P. A. (2011). Lesbian, Gay, Bisexual, and Transgender (LGBT) Physicians' Experiences in the Workplace, Journal of Homosexuality,58:10, 13551371. http://dx.doi.org/10.1080/00918369.2011.614902.

Gates, T. G., \& Viggiani, P. A. (2014). "Understanding lesbian, gay, and bisexual worker stigmatization: a review of the literature", International Journal of Sociology and Social Policy, Vol. 34 Issue: 5/6, pp.359374. https://doi.org/10.1108/IJSSP-07-2013-0077.

Grant, J. M., Mottet, L. A., Tanis, J., Harrison, J., Herman, J. L., \& Keisling, M. (2011). Injustice at Every Turn: A Report of the National Transgender Discrimination Survey. Washington: National Center for Transgender Equality and National Gay and Lesbian Task Force. URL: http://www.thetaskforce.org/injustice-every-turn-report-nationaltransgender-discrimination-survey/.

Konik, J. \& Cortina, L.M. (2008). Policing Gender at Work: Intersections of Harassment Based on Sex and Sexuality, Soc Just Res, 21: 313. https://doi.org/10.1007/s11211-008-0074-z.

Langin, K. (2018) NSF Moves to pilot LGBT questions on national workforce surveys, Science, http://dx.doi.org/10.1126/science/caredit.aav9886.

Lombardi, E. L. , Wilchins, R. A., Priesing, D. \& Malouf, D. (2002). 'Gender Violence', Journal of Homosexuality, 42: 1, $89-101$, http://dx.doi.org/10.1300/J082v42n01 05.

Long, E. (2012). 2011 FGSA Climate Survey. https://www.aps.prg/units/fgsa/upload/FGSA-Climate-Survey.pdf

Mangiafico, S.S. (2016). Summary and Analysis of Extension Program Evaluation in $\mathrm{R}$, version 1.18.1. rcompanion.org/handbook/.

McLeod, P. L., Lobel, S. A., \& Cox, T. H. (1996). Ethnic Diversity and Creativity in Small Groups. Small Group Research, 27(2), 248-264. https://doi.org/10.1177/1046496496272003.

Madera, J.M. (2010). The cognitive effects of hiding one's homosexuality in the workplace. Industrial \& Organizational Psychology, 3(1): p. 86-89. https://doi.org/10.1111/j.1754-9434.2009.01204.x.

Nakagawa, Shinichi. "A Farewell to Bonferroni: The Problems of Low Statistical Power and Publication Bias." Behavioral Ecology 15, no. 6 (November 2004): 1044-45. https://doi.org/10.1093/beheco/arh107.

National Academies of Sciences, Engineering, and Medicine (2018). Sexual Harassment of Women: Climate, Culture, and Consequences in Academic Sciences, Engineering, and Medicine. Washington, DC: The National Academies Press. https://doi.org/10.17226/24994.

Navarro, D. J. (2015) Learning statistics with R: A tutorial for psychology students and other beginners. (Version 0.5) University of Adelaide. Adelaide, Australia.

Neff, G. (2012). Venture labor: work and the burden of risk in innovative industries. Cambridge, Mass: MIT Press. https://www.jstor.org/stable/j.ctt5vjrp8.

Ozeren, E. (2014). Sexual orientation discrimination in the workplace: A systematic review of literature. Procedia-Social and Behavioral Sciences, 109: p. 1203-1215. https://doi.org/10.1016/j.sbspro.2013.12.613.

R Core Team (2018). R: A language and environment for statistical computing. R Foundation for Statistical Computing, Vienna, Austria. URL https://www.Rproject.org/.

Rabelo, V. C., \& Cortina, L. M. (2014). Two Sides of the Same Coin: Gender Harassment and Heterosexist Harassment in LGBQ Work Lives. Law and Human Behavior. Advance online publication. http://dx.doi.org/10.1037/lhb0000087.

Rhoton, L. A. (2011). Distancing as a gendered barrier: Understanding women scientists' gender practices. Gender \& Society, 25, 696-716. http://dx.doi.org/10.1177/0891243211422717. 
Schilt, K., \& Connell, C. (2007). Do workplace gender transitions make gender trouble? Gender, Work and Organization, 14, 596-618. http://dx.doi.org/10.1111/j.1468-0432.2007.00373.x.

Settles, I. H., L. M. Cortina, J. Malley, and A. J. Stewart (2006), The climate for women in academic science: The good, the bad, and the changeable, Psychol. Women Q., 30(1), 47-58. https://doi.org/10.1111/j.1471-6402.2006.00261.x.

Andri Signorell et mult. al. (2019). DescTools: Tools for descriptive statistics. $R$ package version 0.99.27. https://CRAN.R-project.org/package=DescTools.

Suri, M. (2015). Why is science so straight? New York Times, 4 September 2015. URL: https://www.nytimes.com/2015/09/05/opinion/manil-suri-why-isscience-so-straight.html.

Vedres, B., \& Stark, D. (2010). Structural Folds: Generative Disruption in Overlapping Groups. American Journal of Sociology, 115(4), 1150-1190. https://doi.org/10.1086/649497.

Watson, W. E., Kumar, K., \& Michaelsen, L. K. (1993). Cultural Diversity's Impact on Interaction Process and Performance: Comparing Homogeneous and Diverse Task Groups. The Academy of Management Journal, 36(3), 590602. https://doi.org/10.2307/256593.

Wickham, H. (2016). ggplot2: Elegant Graphics for Data Analysis. SpringerVerlag New York. https://CRAN.R-project.org/package=ggplot2.

Wickham, H., François, R., Henry, L., and Müller, K. (2018). dplyr: A Grammar of Data Manipulation. R package version 0.7.8. https://CRAN.Rproject.org/package=dplyr.

Williamson, R., Beiler-May, A., Locklear, L., and Clark, M. (2017). Bringing home what I'm hiding at work: The impact of sexual orientation disclosure at work for same-sex couples. Journal of Vocational Behavior, 103, Part A: p. 7-22. https://doi.org/10.1016/j.jvb.2017.08.005.

Wright, P., Ferris, S. P., Hiller, J. S., \& Kroll, M. (1995). Competitiveness through Management Diversity: Effects on Stock Price Valuation. Academy of Management Journal, 38(1), 272-287. https://doi.org/10.2307/256736.

J. B. Yoder and A. Mattheis. Queer in STEM: Workplace experiences reported in a national survey of LGBTQA individuals in science, technology, engineering, and mathematics careers. J. Homosexuality, 63:1, 2016. http://dx.doi.org/10.1080/00918369.2015.1078632. 
Appendix A. Supplemental Tables

\begin{tabular}{|c|c|c|c|c|c|c|c|}
\hline & & & Never & Rarely & Sometimes & Often & $p$ value \\
\hline \multirow[t]{16}{*}{ Peers } & racist & cis, straight & $52 \%(114)$ & $36 \%(79)$ & $11 \%(24)$ & $2 \%(4)$ & 0.27 \\
\hline & & LGBTQ+ & $41 \%(24)$ & $39 \%(23)$ & $19 \%(11)$ & $2 \%(1)$ & \\
\hline & sexist & cis, straight & $22 \%(48)$ & $40 \%(88)$ & $32 \%(70)$ & $6 \%(14)$ & 0.55 \\
\hline & & LGBTQ+ & $19 \%(11)$ & $34 \%(20)$ & $37 \%(22)$ & $10 \%(6)$ & \\
\hline & homophobic & cis, straight & $59 \%(130)$ & $36 \%(79)$ & $5 \%(11)$ & $0 \%(1)$ & 0.003 \\
\hline & & LGBTQ+ & $36 \%(21)$ & $51 \%(30)$ & $10 \%(6)$ & $3 \%(2)$ & \\
\hline & transphobic & cis, straight & $85 \%(185)$ & $13 \%(29)$ & $1 \%(3)$ & $0 \%(1)$ & $<0.001$ \\
\hline & & LGBTQ+ & $61 \%(36)$ & $20 \%(12)$ & $19 \%(11)$ & $0 \%(0)$ & \\
\hline & masc/fem enough & cis, straight & $53 \%(114)$ & $28 \%(61)$ & $17 \%(36)$ & $3 \%(6)$ & 0.06 \\
\hline & & LGBTQ+ & $37 \%(22)$ & $37 \%(22)$ & $17 \%(10)$ & $8 \%(5)$ & \\
\hline & $\begin{array}{l}\text { physical } \\
\text { ability/disability status }\end{array}$ & cis, straight & $47 \%(104)$ & $31 \%(69)$ & $19 \%(41)$ & $3 \%(6)$ & 0.31 \\
\hline & & LGBTQ+ & $38 \%(22)$ & $36 \%(21)$ & $19 \%(11)$ & $7 \%(4)$ & \\
\hline & $\begin{array}{l}\text { mental ability/inability } \\
\text { status }\end{array}$ & cis, straight & $46 \%(102)$ & $33 \%(72)$ & $19 \%(41)$ & $2 \%(5)$ & 0.05 \\
\hline & & LGBTQ+ & $32 \%(19)$ & $39 \%(23)$ & $20 \%(12)$ & $8 \%(5)$ & \\
\hline & religion or lack thereof & cis, straight & $41 \%(91)$ & $30 \%(65)$ & $25 \%(54)$ & $5 \%(10)$ & 0.001 \\
\hline & & LGBTQ+ & $17 \%(10)$ & $38 \%(22)$ & $31 \%(18)$ & $14 \%(8)$ & \\
\hline \multirow[t]{13}{*}{ Supervisors } & racist & cis, straight & $83 \%(180)$ & $14 \%(31)$ & $1 \%(3)$ & $2 \%(4)$ & 0.01 \\
\hline & & LGBTQ+ & $69 \%(41)$ & $22 \%(13)$ & $8 \%(5)$ & $0 \%(0)$ & \\
\hline & sexist & cis, straight & $58 \%(128)$ & $22 \%(49)$ & $14 \%(30)$ & $5 \%(12)$ & 0.16 \\
\hline & & LGBTQ+ & $47 \%(28)$ & $24 \%(14)$ & $25 \%(15)$ & $3 \%(2)$ & \\
\hline & homophobic & cis, straight & $90 \%(197)$ & $8 \%(18)$ & $1 \%(3)$ & $0 \%(1)$ & 0.27 \\
\hline & & LGBTQ+ & $85 \%(50)$ & $10 \%(6)$ & $3 \%(2)$ & $2 \%(1)$ & \\
\hline & transphobic & cis, straight & $94 \%(202)$ & $6 \%(13)$ & $0 \%(1)$ & $0 \%(0)$ & 0.13 \\
\hline & & LGBTQ+ & $86 \%(51)$ & $14 \%(8)$ & $0 \%(0)$ & $0 \%(0)$ & \\
\hline & masc/fem enough & cis, straight & $78 \%(170)$ & $14 \%(31)$ & $6 \%(12)$ & $2 \%(5)$ & 0.18 \\
\hline & & LGBTQ+ & $71 \%(42)$ & $12 \%(7)$ & $12 \%(7)$ & $5 \%(3)$ & \\
\hline & $\begin{array}{l}\text { physical } \\
\text { ability/disability status }\end{array}$ & cis, straight & $79 \%(172)$ & $16 \%(35)$ & $4 \%(9)$ & $1 \%(2)$ & 0.20 \\
\hline & & LGBTQ+ & $71 \%(42)$ & $17 \%(10)$ & $8 \%(5)$ & $3 \%(2)$ & \\
\hline & $\begin{array}{l}\text { mental ability/inability } \\
\text { status }\end{array}$ & cis, straight & $77 \%(168)$ & $14 \%(30)$ & $7 \%(15)$ & $2 \%(4)$ & 0.17 \\
\hline
\end{tabular}




\begin{tabular}{|c|c|c|c|c|c|c|c|}
\hline & & LGBTQ+ & $64 \%(38)$ & $20 \%(12)$ & $12 \%(7)$ & $3 \%(2)$ & \\
\hline & religion or lack thereof & cis, straight & $78 \%(169)$ & $12 \%(27)$ & $7 \%(15)$ & $3 \%(6)$ & 0.013 \\
\hline & & LGBTQ+ & $61 \%(36)$ & $27 \%$ (16) & $12 \%(7)$ & $0 \%(0)$ & \\
\hline \multirow[t]{16}{*}{ Others } & racist & cis, straight & $44 \%(97)$ & $37 \%(81)$ & $17 \%(38)$ & $1 \%(3)$ & 0.25 \\
\hline & & LGBTQ+ & $35 \%(20)$ & $37 \%(21)$ & $25 \%$ (14) & $4 \%(2)$ & \\
\hline & sexist & cis, straight & $14 \%(31)$ & $33 \%(73)$ & $41 \%(90)$ & $11 \%(24)$ & 0.30 \\
\hline & & LGBTQ+ & $18 \%(10)$ & $23 \%$ (13) & $42 \%(24)$ & $18 \%(10)$ & \\
\hline & homophobic & cis, straight & $50 \%(110)$ & $39 \%(86)$ & $10 \%(21)$ & $1 \%(2)$ & 0.08 \\
\hline & & LGBTQ+ & $42 \%(24)$ & $35 \%(20)$ & $19 \%(11)$ & $4 \%(2)$ & \\
\hline & transphobic & cis, straight & $75 \%(161)$ & $22 \%(47)$ & $4 \%(8)$ & $0 \%(0)$ & 0.02 \\
\hline & & LGBTQ+ & $65 \%(37)$ & $21 \%(12)$ & $12 \%(7)$ & $2 \%(1)$ & \\
\hline & masc/fem enough & cis, straight & $41 \%(90)$ & $36 \%(79)$ & $18 \%(39)$ & $5 \%(10)$ & 0.34 \\
\hline & & LGBTQ+ & $35 \%(20)$ & $32 \%(18)$ & $25 \%(14)$ & $9 \%(5)$ & \\
\hline & $\begin{array}{l}\text { physical } \\
\text { ability/disability status }\end{array}$ & cis, straight & $41 \%(89)$ & $36 \%(78)$ & $21 \%(46)$ & $2 \%(5)$ & 0.74 \\
\hline & & LGBTQ+ & $37 \%(21)$ & $33 \%(19)$ & $26 \%(15)$ & $4 \%(2)$ & \\
\hline & $\begin{array}{l}\text { mental ability/inability } \\
\text { status }\end{array}$ & cis, straight & $35 \%(74)$ & $42 \%(92)$ & $22 \%(48)$ & $2 \%(4)$ & 0.06 \\
\hline & & LGBTQ+ & $39 \%(22)$ & $32 \%(18)$ & $21 \%(12)$ & $9 \%(5)$ & \\
\hline & religion or lack thereof & cis, straight & $35 \%(76)$ & $35 \%(76)$ & $22 \%(49)$ & $8 \%(17)$ & 0.43 \\
\hline & & LGBTQ+ & $33 \%(19)$ & $26 \%(15)$ & $28 \%(16)$ & $12 \%(7)$ & \\
\hline
\end{tabular}

Supplemental Table A. Comparing frequency of hearing negative remarks in the workplace LGBTQPAN women and gender minorities to cis, straight women. 


\begin{tabular}{|c|c|c|c|c|}
\hline & & No & Yes & $p$ value \\
\hline \multirow[t]{2}{*}{ Race } & cis, straight & $96 \%(214)$ & $4 \%(8)$ & 0.02 \\
\hline & LGBTQ+ & $88 \%(52)$ & $12 \%(7)$ & \\
\hline \multirow[t]{2}{*}{ physical ability/inability status } & cis, straight & $98 \%(218)$ & $2 \%(4)$ & 0.16 \\
\hline & LGBTQ+ & $95 \%(56)$ & $5 \%(3)$ & \\
\hline \multirow[t]{2}{*}{ mental ability/inability status } & cis, straight & $99 \%(219)$ & $1 \%(3)$ & 0.037 \\
\hline & LGBTQ+ & $93 \%(55)$ & $7 \%(4)$ & \\
\hline \multirow[t]{2}{*}{ sexual orientation } & cis, straight & $100 \%(221)$ & $0 \%(1)$ & $<0.001$ \\
\hline & LGBTQ+ & $90 \%(53)$ & $10 \%(6)$ & \\
\hline \multirow[t]{2}{*}{ gender identity } & cis, straight & $100 \%(221)$ & $0 \%(1)$ & $<0.001$ \\
\hline & LGBTQ+ & $86 \%(51)$ & $14 \%(8)$ & \\
\hline \multirow[t]{2}{*}{ gender or sex } & cis, straight & $72 \%(159)$ & $28 \%(63)$ & 0.42 \\
\hline & LGBTQ+ & $66 \%(39)$ & $34 \%(20)$ & \\
\hline \multirow[t]{2}{*}{ religion or lack thereof } & cis, straight & $96 \%(213)$ & $4 \%(9)$ & 0.48 \\
\hline & LGBTQ+ & $93 \%(55)$ & $7 \%(4)$ & \\
\hline
\end{tabular}

Supplemental Table B. Feeling unsafe, comparing LGBTQPAN women and gender minorities to cis, straight women.

\begin{tabular}{|c|c|c|c|c|c|c|}
\hline & & Never & Rarely & Sometimes & Often & $p$-value \\
\hline \multirow[t]{2}{*}{ Race } & cis, straight & $93 \%(202)$ & $4 \%(9)$ & $3 \%(6)$ & $0 \%(1)$ & 0.61 \\
\hline & LGBTQ+ & $91 \%(53)$ & $5 \%(3)$ & $2 \%(1)$ & $2 \%(1)$ & \\
\hline \multirow[t]{2}{*}{ physical ability/disability } & cis, straight & $99 \%(214)$ & $1 \%(2)$ & $0 \%(0)$ & $0 \%(1)$ & 0.28 \\
\hline & LGBTQ+ & $96 \%(55)$ & $2 \%(1)$ & $2 \%(1)$ & $0 \%(0)$ & \\
\hline \multirow[t]{2}{*}{ mental ability/disability } & cis, straight & $99 \%(215)$ & $0 \%(0)$ & $0 \%(1)$ & $0 \%(1)$ & 0.04 \\
\hline & LGBTQ+ & $95 \%(54)$ & $4 \%(2)$ & $2 \%(1)$ & $0 \%(0)$ & \\
\hline \multirow[t]{2}{*}{ sexual orientation } & cis, straight & $97 \%(211)$ & $2 \%(5)$ & $0 \%(1)$ & $0 \%(0)$ & 0.005 \\
\hline & LGBTQ+ & $86 \%(50)$ & $10 \%(6)$ & $3 \%(2)$ & $0 \%(0)$ & \\
\hline \multirow[t]{2}{*}{ gender ID } & cis, straight & $99 \%(214)$ & $0 \%(1)$ & $1 \%(2)$ & $0 \%(0)$ & 0.10 \\
\hline & LGBTQ+ & $95 \%(53)$ & $4 \%(2)$ & $2 \%(1)$ & $0 \%(0)$ & \\
\hline \multirow[t]{2}{*}{ Gender/Sex } & cis, straight & $60 \%(130)$ & $26 \%(56)$ & $12 \%(26)$ & $3 \%(6)$ & 0.11 \\
\hline & LGBTQ+ & $53 \%(31)$ & $19 \%(11)$ & $24 \%(14)$ & $3 \%(2)$ & \\
\hline \multirow[t]{2}{*}{ Religion } & cis, straight & $90 \%(195)$ & $6 \%(12)$ & $4 \%(8)$ & $0 \%(1)$ & 0.03 \\
\hline & LGBTQ+ & $84 \%(48)$ & $16 \%(9)$ & $0 \%(0)$ & $0 \%(0)$ & \\
\hline
\end{tabular}

Supplemental Table C. Comparing frequency of verbal harassment for LGBTQPAN women and gender minorities to cis, straight women. 


\begin{tabular}{|l|l|l|l|l|l|c|}
\hline & & Never & Rarely & Sometimes & Often & p-value \\
\hline Race & cis, straight & $100 \%(218)$ & $0 \%(1)$ & $0 \%(0)$ & $0 \%(0)$ & 1 \\
\hline & LGBTQ+ & $100 \%(57)$ & $0 \%(0)$ & $0 \%(0)$ & $0 \%(0)$ & \\
\hline physical ability/disability & cis, straight & $100 \%(217)$ & $0 \%(1)$ & $0 \%(0)$ & $0 \%(0)$ & 0.37 \\
\hline & LGBTQ+ & $98 \%(56)$ & $2 \%(1)$ & $0 \%(0)$ & $0 \%(0)$ & \\
\hline mental ability/disability & cis, straight & $100 \%(217)$ & $0 \%(1)$ & $0 \%(0)$ & $0 \%(0)$ & 1 \\
\hline & LGBTQ+ & $100 \%(57)$ & $0 \%(0)$ & $0 \%(0)$ & $0 \%(0)$ & \\
\hline sexual orientation & cis, straight & $100 \%(215)$ & $0 \%(1)$ & $0 \%(0)$ & $0 \%(0)$ & 1 \\
\hline & LGBTQ+ & $100 \%(57)$ & $0 \%(0)$ & $0 \%(0)$ & $0 \%(0)$ & \\
\hline gender ID & cis, straight & $100 \%(218)$ & $0 \%(0)$ & $0 \%(0)$ & $0 \%(0)$ & 1 \\
\hline & LGBTQ+ & $100 \%(57)$ & $0 \%(0)$ & $0 \%(0)$ & $0 \%(0)$ & \\
\hline Gender/Sex & cis, straight & $91 \%(198)$ & $5 \%(11)$ & $3 \%(7)$ & $0 \%(1)$ & 0.006 \\
\hline & LGBTQ+ & $79 \%(45)$ & $19 \%(11)$ & $2 \%(1)$ & $0 \%(0)$ & \\
\hline Religion & cis, straight & $100 \%(214)$ & $0 \%(0)$ & $0 \%(0)$ & $0 \%(0)$ & 1 \\
\hline & LGBTQ+ & $100 \%(56)$ & $0 \%(0)$ & $0 \%(0)$ & $0 \%(0)$ & \\
\hline
\end{tabular}

Supplemental Table D. Comparing frequency of physical harassment for LGBTQPAN women and gender minorities to cis, straight women. 